\title{
Ontogeny of MMPs and TIMPs in the Murine Neocortex
}

\author{
NATHALIE BEDNAREK, YAN CLÉMENT, VINCENT LELIÈVRE, PAUL OLIVIER, GAUTHIER LORON, \\ ROSELYNE GARNOTEL, AND PIERRE GRESSENS
}

\begin{abstract}
Inserm, U676 [N.B., V.L., P.O., G.L., P.G.], Paris 75019, France; Faculté de Médecine Denis Diderot [N.B., P.O., G.L., P.G.], Université Paris 7, Paris 75019, France; Alix de Champagne [N.B., G.L.], Service de Médecine Néonatale, Reims 51100, France; AP HP, Service de Neurologie Pédiatrique [P.G.], Hôpital Robert Debré, Paris 75019, France; CNRS, UMR 6237 [R.G., Y.C.], Université de Reims Champagne-Ardenne, Reims Cedex 51095, France
\end{abstract}

\begin{abstract}
Matrix metalloproteinases (MMPs) and their tissue inhibitors (TIMPs) have been implicated in normal brain development, adult stroke, and, more recently, perinatal brain injury. Here, our objective was to obtain comprehensive and comparative data on the ontogeny of MMP-2, MMP-9, TIMP-1, and TIMP-2 in the neocortex of male and female mice belonging to various strains, from embryonic life to adulthood. We used gelatin zymography, ELISA, and real-time PCR analyses. MMP-2, MMP-9, and TIMP-1 activity and/or expression peaked during embryonic life and the early neonatal period, whereas TIMP-2 peaked during the first two postnatal weeks. Comparable results were obtained in all the mouse strains except BALB/c, where MMP-2 levels were considerably lower at all ages compared with the other strains. No gender effect was observed on any of the study parameters. This comprehensive study will serve as a basis for future investigations into the role for MMPs and TIMPs in normal brain development and prenatal brain injury. (Pediatr Res 65: 296-300, 2009)
\end{abstract}

$\mathrm{M}$ atrix metalloproteinases (MMPs) are a family of zinccontaining endopeptidases capable of degrading the extracellular matrix (ECM). Matrix degradation occurs during tissue remodeling and inflammatory reactions. MMPs cleave many other important molecules including growth factors, cytokines, and chemokines. Therefore, the role for MMPs extends far beyond the normal and disease-related processes involving structural ECM changes (1).

MMPs and their naturally occurring inhibitors known as tissue inhibitors of metalloproteinases (TIMPs) are expressed by all the main nervous-system cell types including neurons, astrocytes, oligodendrocytes, and microglia (2-5). MMPs (most notably MMP-2, -3, and -9) and TIMPs are essential for coordinated ECM remodeling (6-9). ECM remodeling is probably very important for CNS development, as extensive cellular migration and remodeling are required $(10,11)$. In addition, studies of the spatiotemporal expression of many MMPs (including MMP-2, -3, -9, -12, -14, and -24) suggest a role in various steps of brain development (review in Ref. 1). For example, oligodendrocytes express MMP-9 during migra-

Received June 25, 2008; accepted October 142008

Correspondence: Nathalie Bednarek, M.D., Institut Alix de Champagne, Neonatal and Pediatric Intensive Care Units, CHU, 49 rue Cognacq-Jay, 51092 Reims Cedex, France; e-mail: nbednarek@chu-reims.fr

Supported, in part, by a grant from American Memorial Inc (Boston, Reims); the Sixth Framework Program of the European Commission (contract \#LSHM- CT-2006-036534/ neobrain); and Inserm, Université Paris 7. tion and process extension (5), and MMP-9 is involved in myelination $(12,13)$. Similarly, MMP-9 is expressed during mouse neuronogenesis, suggesting a role in neuronal production (14). Finally, MMP-2, $-3,-9$, and -24 are strongly expressed in the developing cerebellum (review in Ref. 1). Interestingly, TIMPs exert physiologic effects in the CNS independently from their inhibitory actions. They appear to be involved in neuronal death, axonal sprouting, and synaptic mechanisms underlying learning and memory in mice (1517). Excessive expression of MMPs and TIMPs may result in tissue damage. Accumulating evidence supports a major role for MMP-2 and -9 and their respective inhibitors in the pathogenesis of various injuries to the adult or immature brain. Recent studies in mouse null mutants showed a pivotal role for MMP-9 in recovery from traumatic brain injury (18). MMP-9 gene suppression has beneficial long-term effects on neurovascular remodeling and behavioral recovery after stroke (19) and exerts neuroprotective effects against hypoxic-ischemic injury in the immature brain (20). Similarly, structural and functional CNS recovery after injury is impaired in MMP-2 null mice, which exhibit increased glial scarring and reduced axonal plasticity (21). Increased TIMP-1 expression was found in the adult rat CNS after kainate-induced excitotoxic seizures (22), suggesting a neuroprotective effect of this inhibitor. TIMP-1 and TIMP-2 gene transfer via an adenoviral vector in a mouse model of global cerebral ischemia was neuroprotective (23). Thus, MMPs and TIMPs-most notably MMP-2, MMP-9, TIMP-1, and TIMP-2-may be involved both in normal CNS development and in hypoxic-ischemic and inflammatory brain damage. Few comprehensive descriptions of the ontogeny of MMP-2, MMP-9, TIMP-1, and TIMP-2 in the mouse brain are available $(14,24)$. Here, we used zymography, ELISA, and real-time PCR for a comparative descriptive study of the ontogeny of MMP-2, MMP-9, TIMP-1, and TIMP-2 in the neocortex of male and female mice belonging to various strains, from embryonic life to adulthood.

\footnotetext{
Abbreviations: E, embryonic day; ECM, extracellular matrix; MMP, matrix metalloproteinases; $\mathbf{P}$, postnatal day; TIMP, tissue inhibitor of metalloproteinases
} 


\section{METHODS}

Animal specimens. Experimental protocols were approved by our institutional review board, met INSERM guidelines, and were carried out in accordance with the Guide for the Care and Use of Laboratory Animals as adopted and promulgated by the U.S. National Institutes of Health. All animals were kept in a ventilated room under controlled conditions of lighting (12-h light/dark cycle) and temperature $\left(22 \pm 2^{\circ} \mathrm{C}\right)$ and were given free access to food and water. We used five mouse strains: C57BL/6, C3H, BALB/c, FVB, and Swiss. The animals were killed by decapitation. Gender was determined on the day of birth ( $\mathrm{P} 0)$ and confirmed after death, by visual inspection. The neocortex was dissected at the following embryonic (E) and postnatal (P) ages: E14, E17, P0, P5, P10, P15, P21, P30, and P60. The specimens were immediately frozen in isopentane and stored at $-80^{\circ} \mathrm{C}$ until further use.

Gelatin zymography. MMP-2 and MMP-9 activities were determined by gelatin zymography. Frozen brain specimens were homogenized and solubilized in lysis buffer containing $50 \mathrm{mM}$ Tris $\mathrm{pH} 8,150 \mathrm{mM} \mathrm{NaCl}$, and Complete Mini EDTA-free Cocktail Protease Inhibitor (Roche, Meylan, France). Homogenates were centrifuged at $14,000 \mathrm{rpm}$ for $10 \mathrm{~min}$ at $4^{\circ} \mathrm{C}$. Total protein concentrations in the supernatants were determined using $\mathrm{Bi}$ uret's method. Brain samples (100 $\mu \mathrm{g}$ protein) diluted in TAE buffer were run on a $9 \%$ polyacrylamide gel containing $0.1 \%$ gelatin in Tris-glycin SDS, using standard conditions.

Then, the gel was incubated with zymogram-renaturing buffer $(2.5 \%$ triton $\times 100$ ), with gentle agitation, for two 30 -min periods at room temperature. The gel was incubated in fresh zymogram-renaturing buffer overnight at $37^{\circ} \mathrm{C}$. Coomassie blue G 250 diluted in fixative (methanol/acid acetic/ water: 50/10/40) followed by destaining (methanol/acetic acid/water: 50/10/ 40) was used to reveal protease activity. Human recombinant MMP-9 and MMP-2 (Millipore, Bedford, MA) served as internal standards. Areas of gelatinolytic activity were measured using automated image analysis (VilbertLourmat, Marne-la-Vallée, France).

Enzyme-linked immunosorbent assay. MMP-2, TIMP-1, and TIMP-2 levels were determined using ELISA. Quantikine human-mouse MMP-2, human TIMP-2, and mouse TIMP-1 commercial ELISA kits (R\&D System, Lille, France) were used as directed. No sample dilution was required.

Expression of MMP mRNAs. Total RNA was extracted according to a protocol derived from the original procedures of Chomczynski and Sacchi (25) and consisting of two independent total RNA extractions separated by a DNA set treatment (DNA-free kit, Ambion, Austin, TX). RNA quality and concentration were assessed based on relative absorbance at 260 versus 280 $\mathrm{nm}$, and RNA integrity was checked by electrophoresis on $1.5 \%$ agarose gel with ethidium bromide. Total RNA (900 ng) was subjected to reverse transcription using the Iscript kit from Bio-Rad (Hercules, CA). Negative controls (samples without reverse transcriptase) were individually amplified by PCR using the various study primer sets, to ensure absence of genomic DNA contamination. To specifically amplify mRNA encoding various mouse proteins, we designed specific primer sets (sense and antisense, respectively) using Oligo6.0 and M-fold software (Invitrogen, Carlsbad, California). The primer sequences are given in Table 1. Preliminary experiments showed that glyceraldehyde-3-phosphate dehydrogenase (GAPDH) levels were extremely stable in in vivo samples and treatment conditions (26). Therefore, we chose this housekeeping gene to standardize our quantitative experiments. Real-time PCR was set up using SYBR green-containing supermix from Bio-Rad for 50 cycles of a three-step procedure, including a 20 -s denaturation step at $96^{\circ} \mathrm{C}$, a 25 -s annealing step at $61^{\circ} \mathrm{C}$, and a 20 -s extension step at $72^{\circ} \mathrm{C}$. Amplification specificity was assessed by melting curve analysis. The cycle threshold (CT) values obtained by real-time PCR were quantified using a relative standard curve. For this purpose, 8 dilutions (obtained by 2 -fold serial dilution) of a pool of cDNAs were quantified. Results were expressed as the target/internal standard (GAPDH) concentration ratio of the sample divided by the target/internal standard concentration ratio of the calibrator.

Statistical analyses. Quantitative data were expressed as means \pm SEM for each experimental group. Statistical analysis of the data were performed using one- or two-way ANOVA with Dunnett's or Bonferroni's post hoc comparison tests (GraphPad (4) Prism version for Windows; GraphPad Software, San Diego, CA).

\section{RESULTS}

Matrix metalloproteinase-2. By gelatin zymography and ELISA, neocortical MMP-2 activity and concentration were highest in the embryonic period and at birth (P0) then decreased gradually until adulthood (Figs. $1 A$ and 2). These declines in MMP-2 activity and level occurred in all five mouse strains (Fig. 2, ANOVA 1). In BALB/c mice, however, MMP-2 levels were considerably lower at all ages studied, compared with the other strains (Fig. $2 F$, ANOVA 2). No gender effect was found for MMP-2 levels by ELISA in any of the mouse strains (Fig. 1B). In Swiss mice, the results of real-time PCR analysis of MMP-2 mRNA (Fig. 3A, ANOVA 1) were generally comparable with those obtained by gelatin zymography and ELISA (Figs. $1 A$ and $2 B$, ANOVA 1) with, however, a few differences, such as longer lasting mRNA expression (until P5 instead of E17). No gender effect of real-time PCR data were noted (data not shown).

Matrix metalloproteinase-9. Gelatin zymography (Fig. 1A) showed weak MMP-9 activity between E14 and P5. After P5, no MMP-9 was detected in any of the strains (data shown only for Swiss mice). No gender effect was observed (Fig. 1B). Given the lower sensitivity of ELISA compared with gelatin zymography (nanograms versus picograms) and the very low MMP-9 activity by gelatin zymography, MMP-9 ELISA was not performed. The results of real-time PCR analysis (Fig. 3B) of MMP-9 mRNA were comparable with those obtained by gelatin zymography. No gender effect was noted for real-time PCR results (data not shown).

Tissue inhibitors of metalloproteinase-1. TIMP-1 mRNA expression assessed by real-time PCR was highest between E14 and P10 then decreased gradually until P60 (Fig. 3C, ANOVA 1). ELISA showed a similar profile with strong TIMP-1 protein expression during a shorter period ( $\mathrm{P} 5$ versus P10) (Fig. 4). No gender effect was observed (data not shown).

Tissue inhibitors of metalloproteinase-2. TIMP-2 protein could not be evaluated by ELISA because the human TIMP-2 ELISA performed poorly and no mouse TIMP-2 ELISA kit

Table 1. Sequences of primers used in quantitative real time PCR

\begin{tabular}{|c|c|c|c|c|}
\hline Genes & Primer sequences & Amplicon sizes (bp) & Spanning regions & NBI access \\
\hline GAPDH & $\begin{array}{l}\text { 5'-GGCCTTCCGTGTTCCTAC-3'OH, } \\
\text { 5'-TGTCATCATACTTGGAGGTT-3'OH }\end{array}$ & 80 & $1093-1173$ & XM111622 \\
\hline MMP-2 & $\begin{array}{l}\text { 5'-AACTTCCGATTATCCCATGAT-3'OH } \\
5^{\prime} \text {-GGCCAGTACCAGTGTCAGTA-3'OH }\end{array}$ & 87 & $1585-1672$ & NM008610 \\
\hline MMP-9 & 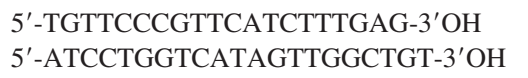 & 103 & $872-975$ & NM013599 \\
\hline TIMP-1 & $\begin{array}{l}\text { 5'-CAGTAAGGCCTGTAGCTGTGC-3'OH } \\
5^{\prime} \text {-AGGTGGTCTCGTTGATTTCTG-3'OH }\end{array}$ & 109 & $227-336$ & NM011593 \\
\hline TIMP-2 & $\begin{array}{l}5^{\prime} \text {-GGAATGACATCTATGGCAACC-3'OH } \\
5^{\prime} \text {-GGCCGTGTAGATAAACTCGAT-3'OH }\end{array}$ & 103 & $24-127$ & AY622854 \\
\hline
\end{tabular}




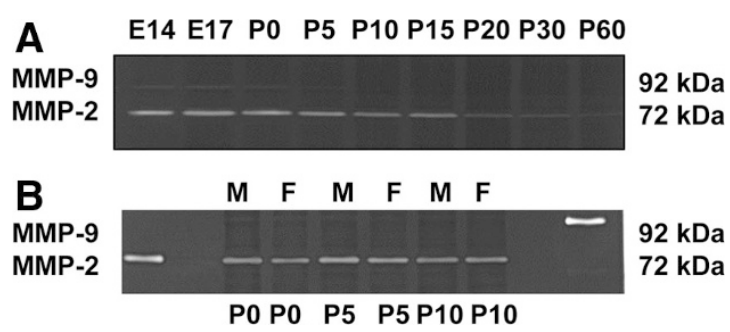

Figure 1. Gelatinolytic activities of MMP-2 and MMP-9 studied by zymography in Swiss mouse neocortex at various embryonic $(E)$ and postnatal $(P)$ ages. The results are representative of three independent experiments. Different animals were studied at each age. $M$, male; $F$, female.

was available. Real-time PCR (Fig. 3D, ANOVA 1) showed a gradual increase in TIMP-2 expression during the embryonic and neonatal period to a peak at P5. Then, TIMP-2 expression decreased until P20, when adult levels were reached. No gender effect was observed (data not shown).

\section{DISCUSSION}

We report detailed descriptive data on the ontogenesis, in the developing mouse neocortex, of two major MMPs, MMP-2 and MMP-9, and of their endogenous inhibitors TIMP-1 and TIMP-2. Of interest, no gender effect was observed for any of the study parameters.

Ontogeny of MMPs and TIMPs in the mouse neocortex. Expression and/or activity of MMP-2, MMP-9, and TIMP-1 were strongest during the embryonic stages, supporting a role for these factors in the control of neuronal proliferation and/or migration, in keeping with earlier studies $(4,5,13,24,27-34)$. The expression of these factors during early postnatal life suggests additional roles in neuronal differentiation and/or survival $(13,35,36)$ and in the events involved in gliogenesis, including migration of astrocytes and oligodendrocyte precursors $(5,12)$.
In contrast, TIMP-2 expression peaked during the first 2 postnatal weeks, suggesting a predominant role for this protein in mechanisms involved in the survival and maturation of postmigratory neurons, such as axonal growth and synaptogenesis; and/or in gliogenesis (35). However, we were unable to assay TIMP-2 protein, a fact that hinders the interpretation of our data. More specifically, we have no information on the balance between protein secretion and mRNA for TIMP- 2 .

The time-course of TIMP-1 expression was comparable with that of MMP-9 expression, suggesting tight control of MMP-9 activity by its endogenous inhibitor. MMP-2 and its inhibitor TIMP-2 differed regarding their expression over time, suggesting a specific role for TIMP-2 in the developing brain, independently from its proteolytic effect on MMP-2. Conceivably, TIMP-2 may act as a constitutive brainmaturation factor (35). To our knowledge, no independent role for TIMP-2 in brain development has been documented to date.

MMP-2 and TIMP-1 mRNAs were expressed for longer periods than the corresponding proteins, suggesting either posttranslational degradation of mRNA or posttranslational regulation.

Our time-course results are consistent with earlier findings. A previous study, conducted in mice aged 1-40 postnatal weeks, showed age-dependent mRNA expression of MMPs and TIMPs, with higher expression levels in the immature brain (24). A broader range of MMPs and TIMPs was examined, compared with our study. Various neuronal tissues in the brain, cerebellum, and spinal cord were investigated, and roles for each MMP and TIMP were suggested based on the results of the spatiotemporal analysis (24). Another study found up-regulation of MMP-9 mRNA in mouse brains during the late embryonic period associated with the development of the neural vascular system (14), in keeping with our results.
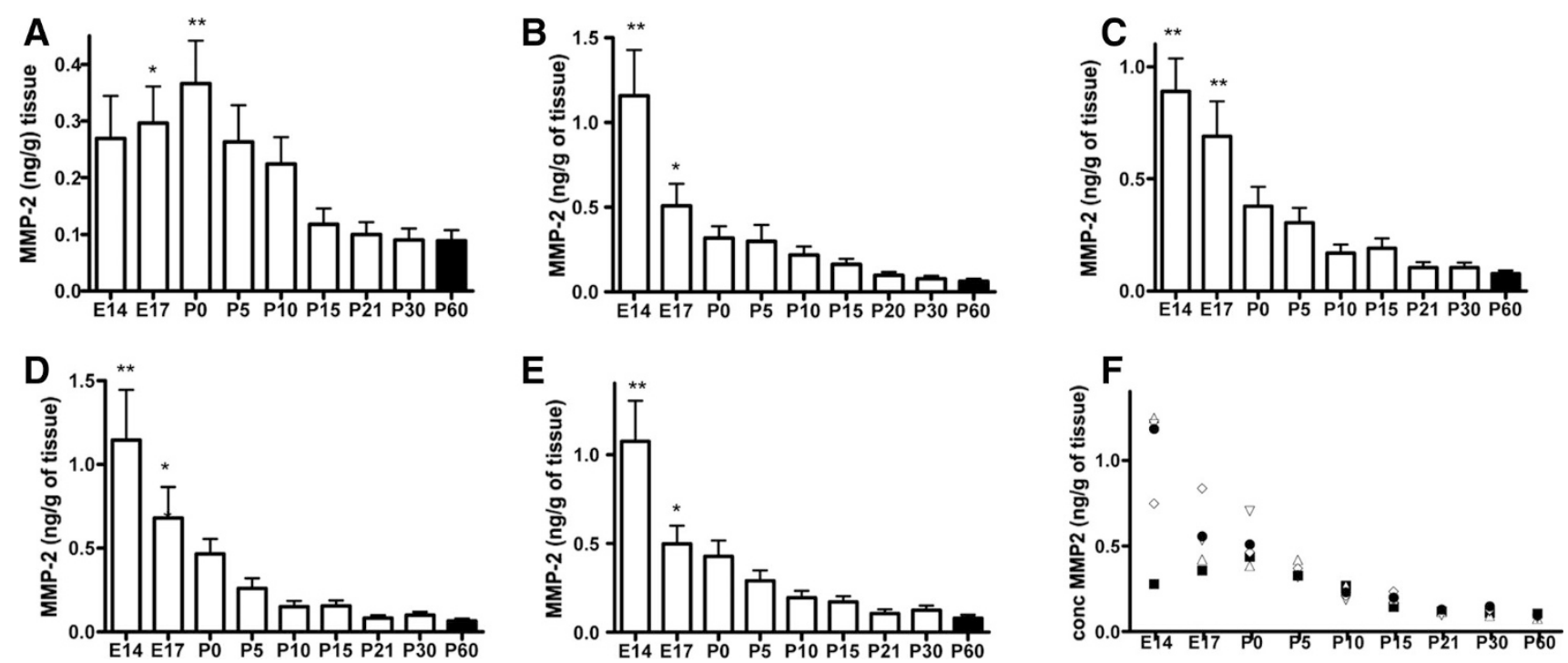

Figure 2. MMP-2 protein level assayed by ELISA in the neocortex of five mouse strains at embryonic $(E)$ and postnatal $(P)$ ages. $(A, \mathrm{BALB} / \mathrm{c} ; B, \mathrm{C} 3 \mathrm{Hen} ; C$, C57BL/6; $D$, FVB; $E$, Swiss; and $F$, summary of all strains (ANOVA 2). Square, Balb; up-triangle: C3Hen; down-triangle: FVB; rhombus: C57BL/6; and circle: Swiss). Six to ten animals were studied in duplicate at each age (males, 3-5; and females, 3-5). Bars represent mean MMP-2 protein concentration \pm SEM. Asterisks indicate statistically significant differences from the P60 group. ${ }^{*} p<0.05$, ** $p<0.01$ by ANOVA 1 with Dunnett's $(A-E)$ or Bonferroni's $(F)$ posttest. 

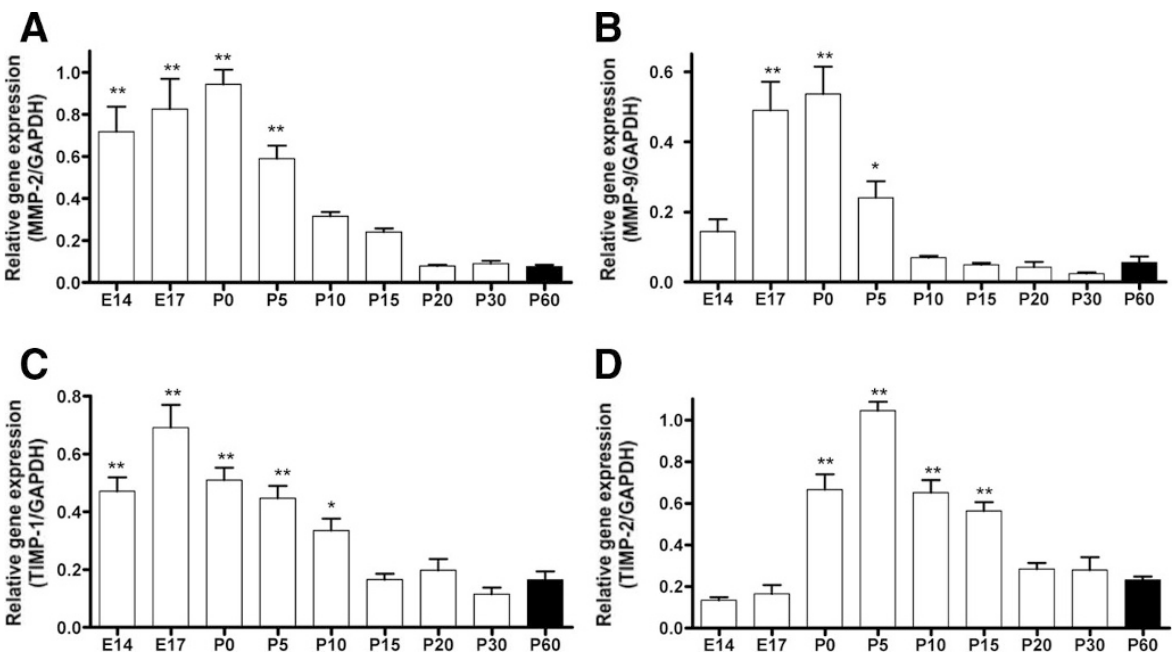

Figure 3. MMP-2 (A), MMP-9 (B), TIMP-1 $(C)$, and TIMP-2 $(D)$ gene expression studied by realtime PCR in Swiss mouse neocortex at various embryonic $(E)$ and postnatal $(P)$ ages. Six to ten animals were studied in duplicate at each age. Bars represent mean brain MMP-2, MMP-9, TIMP-1, or TIMP-2/GAPDH ratios \pm SEM. Asterisks indicate statistically significant differences from the P60 group. $* p<0.05, * * p<0.01$ by ANOVA 1 with Dunnett's posttest.

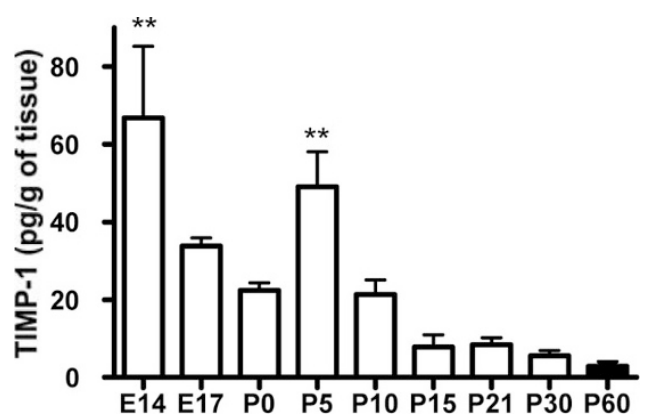

Figure 4. TIMP-1 protein level determined by ELISA in the neocortex of Swiss mice at various embryonic $(E)$ and postnatal $(P)$ ages. Six to ten animals (males, 3-5; and females, 3-5) were studied in duplicate at each age. Bars represent mean TIMP-1 protein concentration \pm SEM. Asterisks indicate statistically significant age differences from the P60 group. ** $p<0.01$ by ANOVA 1with Dunnett's posttest.

In adult mice, we found decreasing yet persistent constitutive MMP-2 expression, absence of detectable MMP-9 expression, and large amounts of TIMP-2, in keeping with earlier data $(4,24)$. TIMP-1 was expressed at a lower level than TIMP-2 $(4,15,24)$.

A weakness of our study is the absence of data on the locations of the metalloproteinases or their inhibitors. MMP-2 has been found chiefly in astrocytes, oligodendrocytes, and cortical neurons (1). MMP-9 has been detected in neurons (30), as well as in endothelial cells, which also contains MMP-2 (15). MMP-9 levels are low in astrocytes (30). TIMP-1 has been found in neurons and in the hippocampus and cerebellum; whereas TIMP-2 has been identified in cortical neurons and in cerebellar Purkinje and granular cells (1). A major strength of our study is that we used the same protocol for all the ages studied. We collected information on the embryonic, very early postnatal, and late postnatal periods, as well as on adulthood. We conducted gender-specific analyses, and we included both the protein concentrations and the activities of MMP-2, MMP-9, and TIMP-1 investigations.

The physiologic interactions of MMPs and TIMPs with the ECM during brain ontogeny deserve to be investigated. MMPs facilitate cell migration by breaking down the ECM. However, in recent years an increasing number of MMP substrates not found in the ECM were identified, including pro-TGF $\beta$,
pro-BDNF, NGF, and VEGF. These growth factors and neurotrophic factors may influence neural development (review in Ref. 37).

Impact of gender and genetic background on MMP and TIMP ontogeny. Several parameters of brain maturation are influenced by gender in rodents $(38,39)$. However, we found no significant effect of gender on any of our study parameters. To our knowledge, no other study has reported a gender effect on the brain expression of MMPs or TIMPs.

A growing body of evidence suggests that genetic polymorphisms and, more generally, the genetic background may have a major influence on resistance or susceptibility to perinatal brain injury (40-42). Oxygen and glucose deprivation and exposure to the glutamate agonist NMDA caused more cell death in neuronal mice cultures from males than from females (43). In rats on P7, hypothermia protected females but not males from histologic damage and sensory-motor deficits (44). Available mouse strains vary regarding their genetic backgrounds and are therefore useful for investigating the influence of the genetic background. Here, we found that most of the strains exhibited similar ontogenic profiles of brain MMP-2 and MMP-9 expression. However, in the BALB/C strain, MMP-2 levels were very low at all the studied ages. This strain probably exhibits a distinctive pattern of brain development or maturity; thus, evidence of accelerated postnatal brain maturation has been found in hybrid BALB/c mice compared with inbred BALB/c mice (45). It would be of considerable interest to investigate the susceptibility of $\mathrm{BALB} / \mathrm{C}$ mice to perinatal brain insults comparatively with other mouse strains. This result supports an influence of the genetic background on the expression of molecules such as MMPs that may play a role in the repair of perinatal brain injury.

The continuum of the levels of expression and activity of MMPs during embryonic, early prenatal, and adult life may inform the development of tests for the early diagnosis of abnormal brain development in humans. Thus, mouse studies may identify avenues for future research that may eventually produce information relevant to the developing and aging human brain. 
Acknowledgments. We thank Prof. Jorge Gallego (INSERM U676) for his invaluable help with the statistical analysis of the data and Prof. Paul Toubas (State of University of New York, Downstate Medical Center, Brooklyn, NY) and Pierre Desautels for their constructive comments about our manuscript.

\section{REFERENCES}

1. Dzwonek J, Rylski M, Kaczmarek L 2004 Matrix metalloproteinases and their endogenous inhibitors in neuronal physiology of the adult brain. FEBS Lett 567:129-135

2. Cross AK, Woodroofe MN 1999 Chemokine modulation of matrix metalloproteinase and TIMP production in adult rat brain microglia and a human microglial cell line in vitro. Glia 28:183-189

3. Gottschall PE, Deb S 1996 Regulation of matrix metalloproteinase expressions in astrocytes, microglia and neurons. Neuroimmunomodulation 3:69-75

4. Pagenstecher A, Stalder AK, Kincaid CL, Shapiro SD, Campbell IL 1998 Differential expression of matrix metalloproteinase and tissue inhibitor of matrix metalloproteinase genes in the mouse central nervous system in normal and inflammatory states. Am J Pathol 152:729-741

5. Uhm JH, Dooley NP, Oh LY, Yong VW 1998 Oligodendrocytes utilize a matrix metalloproteinase, MMP-9, to extend processes along an astrocyte extracellular matrix. Glia 22:53-63

6. Bissell MJ, Hall HG, Parry G 1982 How does the extracellular matrix direct gene expression? J Theor Biol 99:31-68

7. Adams JC, Watt FM 1993 Regulation of development and differentiation by the extracellular matrix. Development 117:1183-1198

8. Damsky CH, Werb Z 1992 Signal transduction by integrin receptors for extracellular matrix: cooperative processing of extracellular information. Curr Opin Cell Biol 4:772-781

9. Matrisian LM, Hogan BL 1990 Growth factor-regulated proteases and extracellular matrix remodeling during mammalian development. Curr Top Dev Biol 24:219-259

10. Condic ML, Letourneau PC 1997 Ligand-induced changes in integrin expression regulate neuronal adhesion and neurite outgrowth. Nature 389:852-856

11. Curran T, D'Arcangelo G 1998 Role of reelin in the control of brain development. Brain Res Brain Res Rev 26:285-294

12. Oh LY, Larsen PH, Krekoski CA, Edwards DR, Donovan F, Werb Z, Yong VW 1999 Gelatinase B/matrix metalloproteinase-9 is required for process outgrowth by oligodendrocytes. J Neurosci 19:8464-8475

13. Larsen PH, DaSilva AG, Conant K, Yong VW 2006 Myelin formation during development of the CNS is delayed in matrix-metalloproteinase- 9 and -12 null mice. J Neurosci 26:2207-2214

14. Canete-Soler R, Gui YH, Linask KK, Muschel RJ 1995 MMP-9 (gelatinase B) mRNA is expressed during mouse neurogenesis and may be associated with vascularization. Brain Res Dev Brain Res 88:37-52

15. Rivera S, Jourquin J, Ogier C, Bernard A, Charton G, Tremblay E, Khrestchatisky M 2004 [The MMP/TIMP system in the nervous system]. Med Sci (Paris) 20:55-60

16. Jourquin J, Tremblay E, Bernard A, Charton G, Chaillan FA, Marchetti E, Roman FS, Soloway PD, Dive V, Viotakis A, Khrestchatisky M 2005 Tissue inhibitor of metalloproteinases-1 (TIMP-1) modulates neuronal death, axonal plasticity, and learning and memory. Eur J Neurosci 22:2569-2578

17. Chaillan FA, Rivera S, Marchetti E, Jourquin J, Werb Z, Soloway PD, Khrestchatisky M, Roman FS 2006 Involvement of tissue inhibition of metalloproteinases-1 in learning and memory in mice. Behav Brain Res 173:191-198

18. Wang X, Jung J, Asahi M, Chwang W, Russo L, Moskowitz MA, Dixon CE, Fini ME, Lo EH 2000 Effects of matrix metalloproteinase-9 gene knock-out on morphological and motor outcomes after traumatic brain injury. J Neurosci 20:7037-7042

19. Zhao BQ, Wang S, Kim HY, Storrie H, Rosen BR, Mooney DJ, Wang X, Lo EH 2006 Role of matrix metalloproteinases in delayed cortical responses after stroke. Nat Med 12:441-445

20. Svedin P, Hagberg H, Savman K, Zhu C, Mallard C 2007 Matrix metalloproteinase-9 gene knock-out protects the immature brain after cerebral hypoxia-ischemia. J Neurosci 27:1511-1518

21. Hsu JY, McKen R, Goussev S, Werb Z, Lee JU, Trivedi A, Noble-Haeusslein LJ 2006 Matrix metalloproteinase-2 facilitates wound healing events that promote functional recovery after spinal cord injury. J Neurosci 26:9841-9850

22. Rivera S, Tremblay E, Timsit S, Canals O, Ben-Ari Y, Khrestchatisky M 1997 Tissue inhibitor of metalloproteinases-1 (TIMP-1) is differentially induced in neu- rons and astrocytes after seizures: evidence for developmental, immediate early gene, and lesion response. J Neurosci 17:4223-4235

23. Magnoni S, Baker A, Thomson S, Jordan G, George SJ, McColl BW, McCulloch J, Horsburgh K 2007 Neuroprotective effect of adenoviral-mediated gene transfer of TIMP-1 and -2 in ischemic brain injury. Gene Ther 14:621-625

24. Birkedal-Hansen H, Cobb CM, Taylor RE, Fullmer HM 1975 Activation of latent bovine gingival collagenase. Arch Oral Biol 20:681-685

25. Docherty AJ, O'Connell J, Crabbe T, Angal S, Murphy G 1992 The matrix metalloproteinases and their natural inhibitors: prospects for treating degenerative tissue diseases. Trends Biotechnol 10:200-207

26. Ulrich R, Gerhauser I, Seeliger F, Baumgartner W, Alldinger S 2005 Matrix metalloproteinases and their inhibitors in the developing mouse brain and spinal cord: a reverse transcription quantitative polymerase chain reaction study. Dev Neurosci 27:408-418

27. Chomczynski P, Sacchi N 1987 Single-step method of RNA isolation by acid guanidinium thiocyanate-phenol-chloroform extraction. Annal Biochem 162:156159

28. Favrais G, Couvineau A, Laburthe M, Gressens P, Lelievre V 2007 Involvement of VIP and PACAP in neonatal brain lesions generated by a combined excitotoxic/ inflammatory challenge. Peptides 28:1727-1737

29. Ayoub AE, Cai TQ, Kaplan RA, Luo J 2005 Developmental expression of matrix proteinases 2 and 9 and their potential role in histogenesis of the cerebellar cortex. J Comp Neurol 481:403-415

30. Muir D 1994 Metalloproteinase dependant neurite outgrowth within a synthetic extracellular matrix is induced by nerve growth factor. Exp Cell Res 210:243-252

31. Zuo J, Ferguson TA, Hernandez YJ, Stetler-Stevenson WG, Muir D 1998 Neuronal matrix metalloproteinase- 2 degrades and inactives a neurite-inhibiting chondroitin sulfate proteoglycan. J Neurosci 18:5203-5211

32. Szklarczyk A, Lapinska J, Rylski M, McKay RD, Kaczmarek L 2002 Matrix metalloproteinase-9 undergoes expression and activation during dendritic remodeling in adult hippocampus. J Neurosci 22:920-930

33. Vecil GG, Larsen PH, Corley SM, Herx LM, Besson A, Goodyer CG, Yong VW 2000 Interleukin-1 is a key regulator of matrix metalloproteinase- 9 expression in human neurons in culture and following mouse brain trauma in vivo. J Neurosci Res 61:212-224

34. Rosenberg GA, Sullivan N, Esiri MM 2001 White matter damage is associated with matrix metalloproteinases in vascular dementia. Stroke 32:1162-1168

35. Sawaya RE, Yamamoto M, Gokaslan ZL, Wang SW, Mohanam S, Fuller GN, McCutcheon IE, Stetler-Stevenson WG, Nicolson GL, Rao JS 1996 Expression and localization of $72 \mathrm{kDa}$ type IV collagenase (MMP-2) in human malignant gliomas in vivo. Clin Exp Metastasis 14:35-42

36. Fager N, Jaworski DM 2000 Differential spatial distribution and temporal regulation of tissue inhibitor of metalloproteinase mRNA expression during rat central nervous system development. Mech Dev 98:105-109

37. Pérez-Martinez L, Jaworski DM 2005 Tissue inhibitor of metalloproteinases-2 promotes neuronal differentiation by acting as an anti-mitogenic signal. J Neurosci 25:4917-4929

38. Okulski P, Jay TM, Jaworski J, Duniec K, Dzwonek J, Konopacki FA, Wilczynski GM, Sánchez-Capelo A, Mallet J, Kaczmarek L 2007 TIMP-1 abolishes MMP-9dependent long-lasting long-term potentiation in the prefrontal cortex. Biol Psychiatry 62:359-362

39. Rosenberg GA 2002 Matrix metalloproteinases in neuroinflammation. Glia 39:279_ 291

40. Kellogg CK, Olson VG, Pleger GL 1998 Neurosteroid action at the GABAA receptor in fetal rat forebrain. Brain Res Dev Brain Res 108:131-137

41. Marin-Husstege M, Muggironi M, Raban D, Skoff RP, Casaccia-Bonnefil P 2004 Oligodendrocyte progenitor proliferation and maturation is differentially regulated by male and female sex steroid hormones. Dev Neurosci 26:245-254

42. Schaefer GB 2008 Genetics considerations in cerebral palsy. Semin Pediatr Neurol $15: 21-26$

43. Johnston MV, Hagberg H 2007 Sex and the pathogenesis of cerebral palsy. Dev Med Child Neurol 49:74-78

44. Hurn PD, Vannucci SJ, Hagberg H 2005 Adult or perinatal brain injury: does sex matter? Stroke 36:193-195

45. Li H, Pin S, Zeng Z, Wang MM, Andreasson KA, McCullough LD 2005 Sex differences in cell death. Ann Neurol 58:317-321

46. Bona E, Hagberg H, Loberg EM, Bagenholm R, Thoresen M 1998 Protective effects of moderate hypothermia after neonatal hypoxia-ischemia: short and long term outcome. Pediatr Res 43:738-745

47. Wahlsten D 1975 Genetic variation in the development of mouse brain and behavior: evidence from the middle postnatal period. Dev Psychobiol 8:371-380 